\title{
Is Total Knee Arthroplasty a Viable Treatment Option in Octogenarians with Advanced Osteoarthritis?
}

\author{
Jai-Gon Seo, $\mathrm{MD}^{1}$, Young-Wan Moon, $\mathrm{MD}^{1}$, Byung-Chul Cho, $\mathrm{MD}^{1}$, Su Cheol Kim, $\mathrm{MD}^{1}$, Young Hoo Ko, $\mathrm{MD}^{1}$, \\ Seung Pil Jang, $\mathrm{MD}^{1}$, and Byung Hoon Lee, $\mathrm{MD}^{2}$ \\ ${ }^{1}$ Department of Orthopaedic Surgery, Samsung Medical Center, Seoul; ${ }^{2}$ Department of Orthopaedic Surgery, Hallym University Kangdong Sacred Heart Hospital, \\ Seoul, Korea
}

\begin{abstract}
Purpose: This study directly compared clinical assessment scores and short-term systemic complications after total knee arthroplasty (TKA) between a group of patients aged 80 or older (141 patients) and another group of patients aged between 65 and 70 years (616 patients) with advanced osteoarthritis.

Materials and Methods: We retrospectively investigated 757 osteoarthritic patients who underwent primary TKA from January 2007 to January 2011 with a follow-up of 1 year. The surgery was performed using an extramedullary alignment guide instrument without invasion of the intramedullary canal to decrease embolic load and blood loss.

Results: At 1 year after surgery, the mean Knee Society knee score was improved in both groups (from 63.6 to 83.2 in octogenarians and from 68.3 to 89.0 in the younger group) and the level of satisfaction was excellent in both groups ( 8 in octogenarians and 8.3 in the younger group), even though there was no notable change in function score in the octogenarians (from 61.0 to 61.9 in the octogenarians and from 62.3 to 73.6 in the younger group). The total incidence of systemic complications (3.4\% vs. $1.2 \%, \mathrm{p}=0.400)$ and surgical complications $(2.1 \%$ vs. $0.5 \%$, $\mathrm{p}=0.229)$ showed no significant difference between groups.

Conclusions: TKA yielded favorable clinical outcomes with a comparatively low postoperative complication rate in octogenarians despite the negligible functional improvement.
\end{abstract}

Keywords: Knee, Osteoarthritis, Arthroplasty, Octogenarian, Clinical assessment scores

\section{Introduction}

As the general population ages, the number of patients with degenerative knees is also increasing. In addition, more patients of advanced age are expressing a desire for surgical treatment to improve their quality of life. Total knee arthroplasty (TKA) is one

Received November 25, 2014; Revised (1st) April 1, 2015;

(2nd) May 12, 2015; (3rd) May 18, 2015; (4th) July 18, 2015;

(5th) July 21, 2015; Accepted July 30, 2015

Correspondence to: Byung Hoon Lee, MD

Department of Orthopaedic Surgery, Hallym University Kangdong

Sacred Heart Hospital, 150 Seongan-ro, Gangdong-gu, Seoul 05355,

Korea

Tel: +82-2-3410-3509, Fax: +82-2-3410-0061

E-mail: oselite@naver.com

This is an Open Access article distributed under the terms of the Creative Commons Attribution Non-Commercial License (http://creativecommons.org/licenses/by-nc/4.0/) which permits unrestricted non-commercial use, distribution, and reproduction in any medium, provided the original work is properly cited. of the most popular surgical treatments for degenerative osteoarthritis of the knee. Many studies have described positive effects of TKA, such as functional improvement, pain relief, and reduced morbidity rate ${ }^{1)}$. However, it has been also reported that TKA results in high 30-day postoperative mortality rates, complication rates, and morbidity rates in patients of advanced age ${ }^{2,3)}$. Moreover, although some studies have shown that TKA may reduce pain and enhance functional ability for patients with advanced arthritis ${ }^{1,4)}$, there are insufficient data on clinical outcomes of TKA for patients over 80 years of age. Postoperative complication rates of patients over 80 years of age vary among studies ${ }^{5)}$, as do comparison results of postoperative clinical assessment scores between patients of advanced age and younger patients ${ }^{6}$. However, many of the previous reports have limitations such as small sample sizes and possible errors during compilation of data from different institutions ${ }^{5}$.

The purpose of our study was 1) to determine whether the improvement after TKA in octogenarians is comparable to that 
in younger patients in terms of comprehensive subjective and functional outcomes and patient satisfaction and 2) to evaluate the difference in short-term postoperative complication rates between the two different age groups after TKA performed using extramedullary instruments at our institution.

\section{Materials and Methods}

We retrospectively investigated 826 patients who underwent primary TKA from January 2007 to January 2011 at our institution. All the patients were classified according to age into the octogenarian group (over 80 years of age) and the younger group (range, 65 to 70 years) and followed up for 1 year after surgery. Indications for TKA were severe knee pain and functional loss unresolved with non-operative treatment modalities, radiographic evidence of advanced osteoarthritic changes (KellgrenLawrence $[\mathrm{K}-\mathrm{L}]$ grade 3 or 4$)^{7}$, and a strong desire for functional enhancement and pain relief. Exclusion criteria were patients with complex knees: 1) less than 50 degrees of knee flexion ( $n=6$ ); and 2) severe varus or valgus deformity (more than 20 degrees) combined with a bone defect requiring bone grafting $(n=10)$. Among 826 patients, 11 patients in octogenarians and 42 patients in the younger group were excluded due to follow-up loss at postoperative 1 year. Consequently, 757 patients were included in the study. The clinical information of patients who had not visited our hospital at the 1-year follow-up session (17 in octogenarians and 16 in the younger group) were collected by telephone, and thus the following information could not be acquired from these patients: range of motion (ROM) and radiographic findings.

The obtained data were reviewed for demographic characteristics, the length of skin incision, total blood loss via drainage for 48 postoperative hours, and duration of surgery (represented by the duration of tourniquet application, which was used for all surgical procedures and deflated only after skin closure). All patients were assessed for comorbidities before the procedure. Significant preoperative morbidity was considered to be present if a patient had an additional medical condition other than hypertension and diabetes that was considered to increase the risk of perioperative complications. Postoperative short-term complications included adverse cardiac events, symptomatic pulmonary embolism, postoperative confusion (delirium), cerebrovascular accidents, mortality within 30 days of surgery, and postoperative deep surgical site infection that were registered by an independent investigator. An arbitrary follow-up period of 1 year was used to define deep surgical site infection as required by the Centers for Disease Control and Prevention criteria. This study was approved by the
Institutional Review Board of the first author's hospital.

All operations were performed by a single senior surgeon (Seo) using a posterior cruciate ligament-substituted implant through Insall's anteromedial approach under tourniquet control ${ }^{8)}$. An extramedullary alignment guide system was used for both the femur and tibia in all patients ${ }^{9}$ (Fig. 1). Femoral and tibial osteotomies were carried out with an extramedullary alignment method: our institution's extramedullary guider and femoro-tibial axis synchronizer (Linker system) ${ }^{10)}$ were placed almost vertical to the mechanical axis to minimize errors ${ }^{9)}$. All knee components were implanted with cement, and the patella was resurfaced with a polyethylene dome-shaped component. The same surgical technique and rehabilitation protocol were used in both groups. Quadriceps-strengthening exercises were started immediately after surgery as basic postoperative rehabilitation, and continuous passive motion exercises were started on the first postoperative day. Ambulation was allowed on the second postoperative day after drainage removal. Thereafter, active and passive joint exercises were allowed within a comfortable ROM. All patients received first-generation cephalosporin as antibiotic prophylaxis until the third postoperative day. Allogenic blood transfusion was performed if the hemoglobin ( $\mathrm{Hb}$ ) level fell below $7.0 \mathrm{mg} / \mathrm{dL}$ or if symptoms of anemia such as dyspnea or tachycardia persisted even after volume replacement in patients with the $\mathrm{Hb}$ level of $7.0-8.0 \mathrm{mg} / \mathrm{dL}^{11-13)}$. All patients were instructed to maintain a single daily dose $(325 \mathrm{mg} / \mathrm{d})$ of enteric-coated aspirin for 6 weeks beginning the day after discharge.

Clinical information was prospectively collected by one independent investigator. Clinical assessments were performed at each follow-up visit. The ROM was assessed using a goniometer

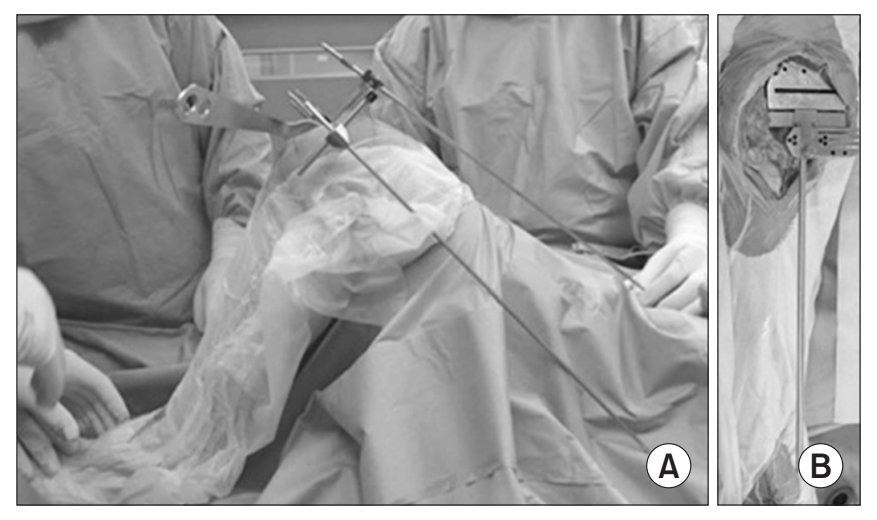

Fig. 1. (A) Extramedullary alignment method using a mechanical axis marker, a sagittal marker, and two guide rods during surgery. (B) Proximal tibial alignment method using femoro-tibial axis synchronizer during surgery. 
with the patient in supine position at 1 month preoperatively and 1 year postoperatively. For pre- and postoperative clinical evaluation, the Knee Society knee and function score (KSKS and KSFS) ${ }^{14)}$ system was used. Patient satisfaction was assessed by a questionnaire using a quantification tool and graded on a scale of 0 to 10 ( 0 , very dissatisfied; 10 , very satisfied). We compared preoperative and 1-year postoperative scores, and investigated preoperative underlying diseases and postoperative complications that developed during hospital stay. Clinical information was collected by telephone in 17 patients in octogenarians and 16 patients in the younger group who had not visited our hospital at 1-year follow-up. Surgical complications were assessed by outpatient follow-up at 1-year after surgery. Radiographic evaluations were performed by an independent investigator at each follow-up visit which was scheduled at 2 months after surgery, 1 year after surgery, and annually thereafter. Full-length (hip-to-ankle) double-leg weight-bearing anteroposterior (AP) radiographs were used to measure coronal limb alignment and coronal alignment of the femoral and tibial components before and after surgery ${ }^{15)}$. Coronal limb alignment was defined as the angle between the mechanical axes of the femur and the tibia. Coronal alignment of the femoral component was defined as the medial angle between a line drawn parallel to the femoral component condyles and the anatomical axis of the femur, and coronal alignment of the tibial component was defined as the medial angle between a line drawn parallel to the tibial component on the AP radiograph and the anatomical axis of the tibia.

With the patient standing, AP, lateral, and Merchant's view radiographs were obtained at every follow-up, and mechanical femoro-tibial alignment (MFTA) was measured on full-length standing AP radiographs using a picture archiving and communication system (GE Healthcare, Milwaukee, WI, USA). All radiographs were obtained with standard positioning (directing the patella anteriorly and with a focal film distance of $100 \mathrm{~cm}$ ).

\section{Statistical Analysis}

The ROM and clinical outcomes (KSKS, KSFS, and patient satisfaction) are described as means and standard deviations. Differences were compared between the two groups using Student's t-test. Demographic data including the incidence of significant preoperative morbidities were compared between the groups by Pearson's chi-square analysis. The association of candidate influential variables and age group was investigated with respect to the binary outcome defined as the incidence of postoperative morbidities. The candidate influential variables included were demographic factors (sex, body mass index [BMI], and significant medical comorbidity) and clinical conditions (operation time and postoperative bleeding). The significance of associations was determined using logistic regression analysis in univariable and multivariable analyses. The statistical analysis in this study had $>80 \%$ power to detect a 10 -point difference in postoperative clinical outcomes between the groups (accepting $<5 \%$ probability of a type I error). The threshold for significance was $<0.05$. Statistical analysis was performed using SAS ver. 9.13 (SAS Institute Inc., Cary, NC, USA).

\section{Results}

There were no significant inter-group differences in patient demographics including sex, K-L grade, average BMI, and prevalence of significant preoperative comorbidities (Table 1). The younger group consisted of 55 males and 561 females and the octogenarian group contained 13 males and 128 females. The mean age of patients was 67.6 years in the younger group and 81.9 years in the octogenarian group (standard deviation: 1.8 and 2.1, respectively). Regarding the K-L classification, 38 patients (6.2\%) in the younger group and 9 patients (6.4\%) in the octogenarian group had grade 3 osteoarthritis. The average BMI was 26.5 in the younger and 27.2 in the octogenarian group. In the octogenarian group, 18 patients (12.7\%) had significant preoperative morbidities, including pre-existing cerebrovascular accidents, arrhythmia, and adverse cardiopulmonary history, compared with 67 patients (10.9\%) in the younger group. Coronal limb alignment and the position of the femoral and tibial components in the coronal plane on postoperative radiographs did not show significant differences between the groups. The average MFTA was

Table 1. Comparison of Demographic Data between the Older and Younger Groups

\begin{tabular}{lccc}
\hline \multicolumn{1}{c}{ Variable } & $\begin{array}{c}\text { Octogenarians } \\
(\mathrm{n}=141)\end{array}$ & $\begin{array}{c}\text { Younger patients }^{\mathrm{a})} \\
(\mathrm{n}=616)\end{array}$ & p-value \\
\hline Age (yr) & $81.9 \pm 2.1$ & $67.7 \pm 1.8$ & $<0.001$ \\
Sex ratio (F:M) & $9.8: 1$ & $9.1: 1$ & $\mathrm{NS}$ \\
$\mathrm{BMI}\left(\mathrm{kg} / \mathrm{m}^{2}\right)$ & $27.2 \pm 3.3$ & $26.5 \pm 3.2$ & $\mathrm{NS}$ \\
$\begin{array}{l}\text { K-L classification } \\
\quad \text { III/IV) }\end{array}$ & $9 / 132$ & $38 / 578$ & NS \\
$\begin{array}{l}\text { Preoperative significant } \\
\text { comorbidity (\%) }\end{array}$ & 12.7 & 10.9 & $\mathrm{NS}$ \\
\hline
\end{tabular}

Values are presented as mean \pm standard deviation.

NS: not significant, BMI: body mass index, K-L classification: KellegrenLawrence classifications.

${ }^{\text {a) Between }} 65$ and 70 years of age. 
varus $1.2^{\circ}$ (standard deviation, $1.5^{\circ}$ ) in the octogenarian group and varus $1.5^{\circ}$ (standard deviation, $2.2^{\circ}$ ) in the younger group. Femoral component coronal angle was $88.8^{\circ}$ (standard deviation, $2.0^{\circ}$ ) in the octogenarian group and $88.4^{\circ}$ (standard deviation, $2.4^{\circ}$ ) in the younger group. Tibial component coronal angle was $90.3^{\circ}$ (standard deviation, $1.4^{\circ}$ ) in the octogenarian group and $90.2^{\circ}$ (standard deviation, $1.5^{\circ}$ ) in the younger group. The average skin incision length was $10.5 \mathrm{~cm}$ in the octogenarian group and $10.9 \mathrm{~cm}$ in the younger group showing no significant inter-group difference.

The mean postoperative KSKS was improved relative to the preoperative values in both groups (from 63.6 to 83.2 in octogenarians and from 68.3 to 89.0 in the younger group). However the octogenarian group showed no improvement in KSFS after

Table 2. Clinical Assessment by the Knee Society Score

\begin{tabular}{lccc}
\hline \multicolumn{1}{c}{ Variable } & Octogenarians & Younger patients $^{\mathrm{a})}$ & p-value \\
\hline Knee Society knee score & & & \\
No. of patients & 124 & 600 & \\
Preoperative & $63.6 \pm 15.7$ & $68.3 \pm 21.3$ & 0.106 \\
Postoperative & $83.2 \pm 18.5$ & $89.0 \pm 14.2$ & 0.118 \\
Knee Society function & & & \\
score & & & \\
No. of patients & 141 & 616 & 0.573 \\
Preoperative & $61.0 \pm 11.2$ & $62.3 \pm 9.3$ & $<0.001$ \\
Postoperative & $61.9 \pm 25.2$ & $73.6 \pm 19.2$ & 0.411 \\
Satisfaction rate (\%) & $8.0 \pm 2.1$ & $8.3 \pm 2.0$ & \\
\hline
\end{tabular}

Values are presented as mean \pm standard deviation.

${ }^{\text {a) Between }} 65$ and 70 years of age.
TKA in contrast to the younger group (from 61.0 to 61.9 in octogenarians and from 62.3 to 73.6 in the younger group). Nonetheless, both groups showed high scores for patient satisfaction (8 in octogenarians and 8.3 in the younger group) and comparison between the age groups did not yield any statistically significant differences in the satisfaction scores ( $\mathrm{p}=0.411)$ (Table 2, Fig. 2).

There was no significant inter-group difference in the incidence of postoperative systemic complications $(2.8 \%$ in the octogenarian group vs. $1.1 \%$ in the younger group; $\mathrm{p}=0.400$ ), and surgical complications $(2.1 \%$ in the octogenarian group vs. $0.5 \%$ in the younger group; $\mathrm{p}=0.229$ ) (Table 3 ). In multivariate regression analysis, none of the postoperative complications was associ-

Table 3. Postoperative Complications in the Two Groups

\begin{tabular}{cccc}
\hline Complication & $\begin{array}{c}\text { Octogenarians } \\
(\mathrm{n}=141)\end{array}$ & $\begin{array}{c}\text { Younger patients } \\
(\mathrm{n}=616)\end{array}$ & p-value \\
\hline Systemic complications (\%) & $4 / 141(2.8)$ & $7 / 616(1.1)$ & 0.400 \\
Adverse cardiac event & 1 & 3 & \\
Cerebrovascular accident & 1 & 2 & \\
Delirium & 2 & 2 & \\
Pulmonary embolism & 0 & 0 & \\
30-day mortality & 0 & 0 & \\
Surgical complications (\%) & $3 / 124(2.4)$ & $3 / 600(0.5)$ & 0.207 \\
Patellar fracture, osteo- & 2 & 1 & \\
necrosis & & & \\
Periprosthetic infection & 1 & 2 & \\
\hline
\end{tabular}

Minor complications including urinary retention and nausea were excluded.

${ }^{\text {a) Between }} 65$ and 70 years of age.
A

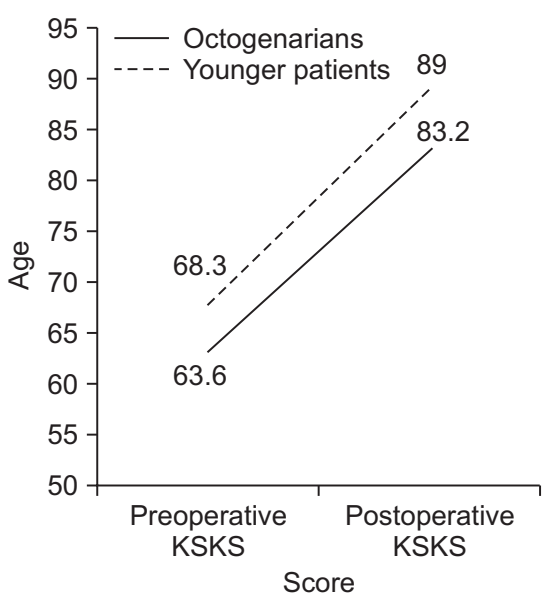

B

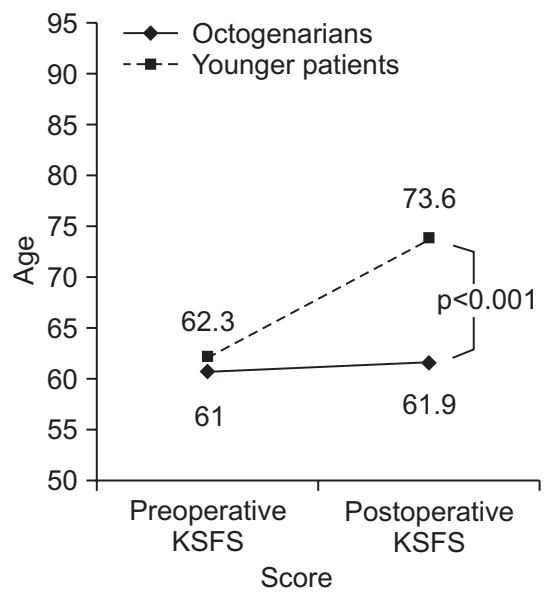

C

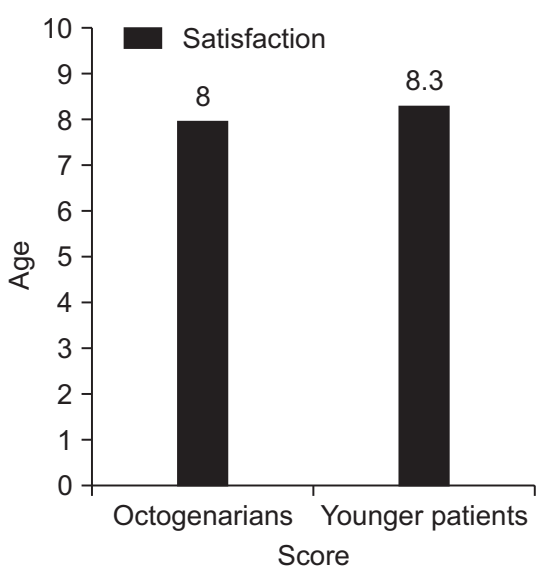

Fig. 2. Comparison of clinical outcomes between two age groups (A) Knee Society Knee Score (KSKS). (B) Knee Society Function Score (KSFS). (C) Satisfaction rate. 
ated with any of the variables tested including age group, sex, duration of operation, total blood drainage volume, and significant preoperative comorbidity. The mean surgery time was $62.8 \pm 1.3$ minutes for the octogenarian group and $60.7 \pm 1.1$ for the younger group, and the difference was not statistically significant $(p=0.226)$. The mean postoperative total blood drainage volume was significantly greater in the octogenarian group than in the younger group $(927.6 \pm 51.9 \mathrm{~mL}$ vs. $772.5 \pm 34.3 \mathrm{~mL} ; \mathrm{p}<0.001)$.

\section{Discussion}

As the number of elderly people increases in the general population, we think it is necessary to confirm the effectiveness and safety of commonly performed procedures in patients of advanced age. Therefore, we compared the enhancement in knee scores and morbidity after TKA performed in our hospital between two groups divided with respect to age. Lately, many reports on palliative TKA in older patients have been published; however, these reports have various problems such as small sample sizes ${ }^{16,17)}$, absence of control group ${ }^{18-20)}$, and uncertainty related to data collection from different institutions ${ }^{5}$. We based our study on large samples of patients who underwent TKA performed by a single high-volume surgeon at one institution.

In terms of the mean KSKS, postoperative enhancement was achieved regardless of age. However, in terms of KSFS, patients over 80 years old showed a significantly lower level of functional improvement. We attributed this to the different subscales used by the knee joint score and functional score: the knee joint score is based on pain, motion angle, stability, and dynamic alignment, whereas the functional score is based on walking distance, stairclimbing, and the use of walking assistance devices. Aged patients may have accompanying spine problems and physical diseases other than the knee disease and other age-related factors might affect the functional score ${ }^{5}$. These results are consistent with those of other studies involving elderly patients ${ }^{20)}$. However, even though the octogenarian group showed a lower KSFS, patients in both groups were very satisfied, with no significant difference in patient satisfaction level between the groups.

The Knee Society score (KSS), the most commonly used scoring system for patient evaluation after TKA, is composed of knee score and function score ${ }^{13)}$ and is based on $75 \%$ subjective and $25 \%$ objective assessments. The KSS alone does not seem to be appropriate for assessment after TKA ${ }^{21)}$. Only a low to moderate association has been observed between self-reported and performance-based tools, and other forms of assessments are needed for thorough evaluation of patient outcome ${ }^{22)}$. Therefore, we assessed patient satisfaction as an alternative outcome mea- sure because there is a well-documented discrepancy between clinician-based and patient-based ratings of health status ${ }^{23,24)}$. This study emphasizes that the effectiveness of TKA in advancedage patients has to be evaluated in various aspects.

For safety, we performed all TKA procedures with extramedullary instruments because this approach has several advantages over the intramedullary system. First, the use of extramedullary instruments in TKA reduces the substantial amount of blood loss caused by femoral canal reaming (range, 145 to $396 \mathrm{~mL})^{25,26)}$ and second, it reduces embolic load by avoiding invasion of the femoral intramedullary canal during TKA ${ }^{27}$. Many researchers have reported that the intramedullary alignment method can lead to fat embolism, increased blood loss, postoperative hypoxia, and surgery-related fractures because it invades the femur medullary canal, and Stern et al. reported that the intramedullary guider causes important hematological and hemodynamic changes ${ }^{26,28,29)}$. Extramedullary reference techniques can reduce such risks by avoiding medullary invasion. We did not directly compare intramedullary and extramedullary procedures in this study. And the main systemic complication occurrence rates in our study ( $2.8 \%$ for the octogenarian group and $1.1 \%$ for the younger age group) were not lower than those in a previous investigation $^{30)}$ using wide American database, National Surgical Quality Improvement Program (the occurrence rate of fatal systemic complications including progressive renal insufficiency, pulmonary embolism, myocardial infarction, septic shock, 30day mortality, stroke, cardiac arrest, and coma of longer than 24 hours were reported as $1.22 \%$ ). Therefore, we acknowledge that this study has limitations that prevent us from drawing definite conclusions regarding the superiority of this technique over the intramedullary method. Nevertheless, no significant difference was observed between the two separate age groups after TKA using the same extramedullary guide system. We assume that, although the causes of development of complications are multifactorial, use of the extramedullary method to avoid invasion of the femoral and tibial medullary canal and reduce postoperative blood loss might have contributed to such results.

Our study has some inherent limitations because of its retrospective design. In addition, we lost several octogenarian patients (7.8\%) to follow-up, which might be related to higher anticipated death rates in the elderly or low compliance with follow-ups.

\section{Conclusions}

TKA provided favorable clinical outcomes with a comparatively low postoperative complication rate in octogenarians in spite of the lower level of functional improvement than in younger pa- 
tients. Our findings may be useful in TKA for patients aged over 80 years in selection of surgical techniques and patient counseling.

\section{Conflict of Interest}

No potential conflict of interest relevant to this article was reported.

\section{References}

1. Callahan CM, Drake BG, Heck DA, Dittus RS. Patient outcomes following tricompartmental total knee replacement. A meta-analysis. JAMA. 1994;271:1349-57.

2. Parry MC, Smith AJ, Blom AW. Early death following primary total knee arthroplasty. J Bone Joint Surg Am. 2011; 93:948-53.

3. Raut VV, Wroblewski BM, Siney PD. Revision hip arthroplasty: can the octogenarian take it? J Arthroplasty. 1993; 8:401-3.

4. Pavone V, Boettner F, Fickert S, Sculco TP. Total condylar knee arthroplasty: a long-term followup. Clin Orthop Relat Res. 2001;(388):18-25.

5. Kennedy JW, Johnston L, Cochrane L, Boscainos PJ. Total knee arthroplasty in the elderly: does age affect pain, function or complications? Clin Orthop Relat Res. 2013; 471:1964-9.

6. Clement ND, MacDonald D, Howie CR, Biant LC. The outcome of primary total hip and knee arthroplasty in patients aged 80 years or more. J Bone Joint Surg Br. 2011;93:1265-70.

7. Petersson IF, Boegard T, Saxne T, Silman AJ, Svensson B. Radiographic osteoarthritis of the knee classified by the Ahlback and Kellgren \& Lawrence systems for the tibiofemoral joint in people aged 35-54 years with chronic knee pain. Ann Rheum Dis. 1997;56:493-6.

8. Insall J. A midline approach to the knee. J Bone Joint Surg Am. 1971;53:1584-6.

9. Seo JG, Moon YW, Lim JS, Park SJ, Kim SM. Mechanical axis-derived femoral component rotation in extramedullary total knee arthroplasty: a comparison between femoral transverse axis and transepicondylar axis. Knee Surg Sports Traumatol Arthrosc. 2012;20:538-45.

10. Lee DH, Seo JG, Moon YW. Synchronisation of tibial rotational alignment with femoral component in total knee arthroplasty. Int Orthop. 2008;32:223-7.

11. Fakhry SM, Fata P. How low is too low? Cardiac risks with anemia. Crit Care. 2004;8 Suppl 2:S11-4.

12. Hebert PC, Wells G, Blajchman MA, Marshall J, Martin C, Pagliarello G, Tweeddale M, Schweitzer I, Yetisir E. A multicenter, randomized, controlled clinical trial of transfusion requirements in critical care: Transfusion Requirements in Critical Care Investigators, Canadian Critical Care Trials Group. N Engl J Med. 1999;340:409-17.

13. Pierson JL, Hannon TJ, Earles DR. A blood-conservation algorithm to reduce blood transfusions after total hip and knee arthroplasty. J Bone Joint Surg Am. 2004;86:1512-8.

14. Insall JN, Dorr LD, Scott RD, Scott WN. Rationale of the Knee Society clinical rating system. Clin Orthop Relat Res. 1989;(248):13-4.

15. McGrory JE, Trousdale RT, Pagnano MW, Nigbur M. Preoperative hip to ankle radiographs in total knee arthroplasty. Clin Orthop Relat Res. 2002;(404):196-202.

16. Belmar CJ, Barth P, Lonner JH, Lotke PA. Total knee arthroplasty in patients 90 years of age and older. J Arthroplasty. 1999;14:911-4.

17. Pagnano MW, McLamb LA, Trousdale RT. Total knee arthroplasty for patients 90 years of age and older. Clin Orthop Relat Res. 2004;(418):179-83.

18. Anderson JG, Wixson RL, Tsai D, Stulberg SD, Chang RW. Functional outcome and patient satisfaction in total knee patients over the age of 75. J Arthroplasty. 1996;11:831-40.

19. Hosick WB, Lotke PA, Baldwin A. Total knee arthroplasty in patients 80 years of age and older. Clin Orthop Relat Res. 1994;(299):77-80.

20. Joshi AB, Markovic L, Gill G. Knee arthroplasty in octogenarians: results at 10 years. J Arthroplasty. 2003;18:295-8.

21. Bullens PH, van Loon CJ, de Waal Malefijt MC, Laan RF, Veth RP. Patient satisfaction after total knee arthroplasty: a comparison between subjective and objective outcome assessments. J Arthroplasty. 2001;16:740-7.

22. Gandhi R, Tsvetkov D, Davey JR, Syed KA, Mahomed NN. Relationship between self-reported and performance-based tests in a hip and knee joint replacement population. Clin Rheumatol. 2009;28:253-7.

23. Janse AJ, Gemke RJ, Uiterwaal CS, van der Tweel I, Kimpen JL, Sinnema G. Quality of life: patients and doctors don't always agree: a meta-analysis. J Clin Epidemiol. 2004;57:65361.

24. Mantyselka P, Kumpusalo E, Ahonen R, Takala J. Patients' versus general practitioners' assessments of pain intensity in primary care patients with non-cancer pain. Br J Gen Pract. 2001;51:995-7. 
25. Chauhan SK, Scott RG, Breidahl W, Beaver RJ. Computerassisted knee arthroplasty versus a conventional jig-based technique: a randomised, prospective trial. J Bone Joint Surg Br. 2004;86:372-7.

26. Kandel L, Vasili C, Kirsh G. Extramedullary femoral alignment instrumentation reduces blood loss after uncemented total knee arthroplasty. J Knee Surg. 2006;19:256-8.

27. Kalairajah Y, Cossey AJ, Verrall GM, Ludbrook G, Spriggins AJ. Are systemic emboli reduced in computer-assisted knee surgery?: a prospective, randomised, clinical trial. J Bone Joint Surg Br. 2006;88:198-202.
28. Fahmy NR, Chandler HP, Danylchuk K, Matta EB, Sunder $\mathrm{N}$, Siliski JM. Blood-gas and circulatory changes during total knee replacement. Role of the intramedullary alignment rod. J Bone Joint Surg Am. 1990;72:19-26.

29. Ishii Y, Ohmori G, Bechtold JE, Gustilo RB. Extramedullary versus intramedullary alignment guides in total knee arthroplasty. Clin Orthop Relat Res. 1995;(318):167-75.

30. Easterlin MC, Chang DG, Talamini M, Chang DC. Older age increases short-term surgical complications after primary knee arthroplasty. Clin Orthop Relat Res. 2013;471:2611-20. 